May 2001 • NREL/TP-500-30070

\title{
Dynamic Characterization Testing of Wind Turbines
}

\section{Richard M. Osgood}

\section{National Renewable Energy Laboratory}

1617 Cole Boulevard

Golden, Colorado 80401-3393

NREL is a U.S. Department of Energy Laboratory

Operated by Midwest Research Institute $\bullet$ Battelle $\bullet$ Bechtel

Contract No. DE-AC36-99-G010337 
May 2001 • NREL/TP-500-30070

\section{Dynamic Characterization Testing of Wind Turbines}

\section{Richard M. Osgood}

Prepared under Task No. WER1.2460

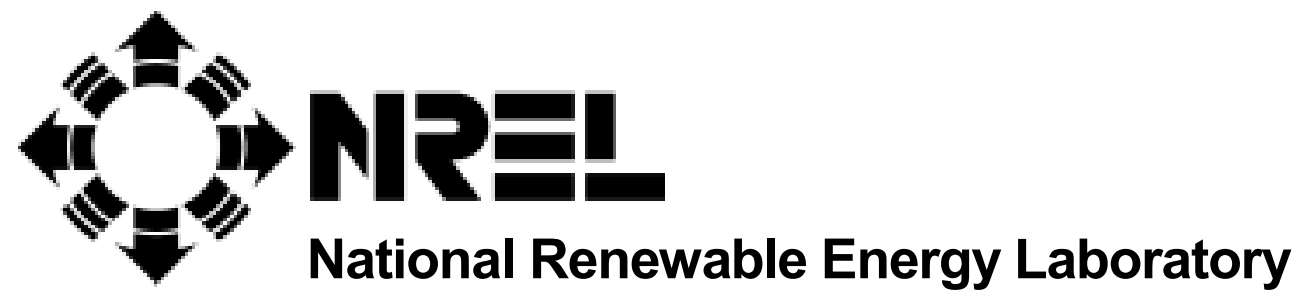

1617 Cole Boulevard

Golden, Colorado 80401-3393

NREL is a U.S. Department of Energy Laboratory

Operated by Midwest Research Institute $\bullet$ Battelle $\bullet$ Bechtel

Contract No. DE-AC36-99-G010337 


\section{NOTICE}

This report was prepared as an account of work sponsored by an agency of the United States government. Neither the United States government nor any agency thereof, nor any of their employees, makes any warranty, express or implied, or assumes any legal liability or responsibility for the accuracy, completeness, or usefulness of any information, apparatus, product, or process disclosed, or represents that its use would not infringe privately owned rights. Reference herein to any specific commercial product, process, or service by trade name, trademark, manufacturer, or otherwise does not necessarily constitute or imply its endorsement, recommendation, or favoring by the United States government or any agency thereof. The views and opinions of authors expressed herein do not necessarily state or reflect those of the United States government or any agency thereof.

Available electronically at http://www.doe.gov/bridge

Available for a processing fee to U.S. Department of Energy

and its contractors, in paper, from:

U.S. Department of Energy

Office of Scientific and Technical Information

P.O. Box 62

Oak Ridge, TN 37831-0062

phone: 865.576.8401

fax: 865.576.5728

email: reports@adonis.osti.gov

Available for sale to the public, in paper, from:

U.S. Department of Commerce

National Technical Information Service

5285 Port Royal Road

Springfield, VA 22161

phone: 800.553.6847

fax: 703.605.6900

email: orders@ntis.fedworld.gov

online ordering: http://www.ntis.gov/ordering.htm

Printed on paper containing at least $50 \%$ wastepaper, including $20 \%$ postconsumer waste 


\section{Abstract}

The U.S. Department of Energy (DOE), in conjunction with the U.S. wind industry, is supporting the development and commercialization of utility-grade wind turbines. Under the Certification Program, the DOE, through the National Renewable Energy Laboratory (NREL) will assist the U.S. wind industry in obtaining American Association for Laboratory Accreditation (A2LA)-type certification for their class of wind turbine. As part of the Certification Program, NREL is conducting a suite of certification tests that are specified by the International Electro-technical Commission (IEC) standards.

One emerging certification requirement is to characterize the dynamic behavior of the wind turbine's operation. Therefore, the purpose of the dynamic characterization tests is to document the fundamental dynamic characteristics of the wind turbine under critical operational modes and fault conditions in light of turbine design specifications. Some of the dynamic characteristics determined from testing include the conformation of natural system frequencies and the wind turbine's dynamic response to typical rated and extreme modes of operation.

This paper discusses NREL's approach in designing and implementing a dynamic characterization test for commercial wind turbines. One important objective of the dynamic characterization test is to provide a Certification Agent with test data to show that the mechanical equipment of the wind turbine is operating within design vibration limits. For NREL's industry participant, the test results are an indication of the wind system's overall quality of mechanical operation that can be used to compare with established industry standards for a wind system's response under typical and extreme operating conditions.

\section{Background \& Rationale}

Dynamic characterization testing of wind turbines evolved from the need to predict maximum operating loads due to design and off-design operating conditions. Typical turbine operating conditions can be grouped into three major modes of operation: (1) transient events such as start-up or emergency-stop operations, (2) rated to extreme power production, and (3) parked or furled standby mode. Some of the largest structural loads resisted by the turbine can occur during emergency-stop events and regulating peak power production through extreme wind gusts. In addition, the growing use of variable-speed wind turbines highlights the need to identify a structural resonance and its critical rotor speed to avoid potentially damaging dynamic loads during turbine operation (1).

Standards are being considered by national and international certification bodies for the dynamic behavior of commercial wind turbines (2). The motivation is to adopt a standard that characterizes a wind turbine in terms of its dynamic behavior from rated to extreme operating conditions. Such a standard would help insure the safety of personnel and protection of the wind turbine system. We have developed a dynamic characterization test (DCT) that is designed to confirm predicted fundamental system and component frequencies and to measure operating vibration levels over a range of rated power conditions, including fault and parked modes of operation (3). We have found four significant DCT results that are useful in characterizing the dynamic behavior of a wind turbine system. These results include:

1) Operating vibration spectra collected for rated and extreme power production

2) Component motion or peak acceleration levels due to transient events

3) Natural system frequencies measured for parked rotor conditions

4) Critical rotor speeds measured during variable-speed operation. 
Our wind industry partners have used DCT results to help them evaluate the operation of different prototype designs. A wind turbine control analysis, for example, uses DCT results taken during operation under different control strategies to compare the structural acceleration fluctuations with different controller algorithms. Another common use of DCT results is to validate maximum operating accelerations due to peak gust events that are predicted by a wind turbine simulation model. In this case, a dynamist will correlate peak operating accelerations predicted by his simulation model with a measured time series of accelerations collected during dynamic characterization tests of the turbine for different operating conditions (4). In addition, other wind turbine researchers routinely use measured natural frequency data to check their analytical estimates of fundamental system frequencies. Dynamic models that are updated with actual natural frequencies provide better simulations of the turbine's dynamic response to both steady state and transient operating conditions (5). We have recently expanded our dynamic characterization test methods to help our industry partners diagnose operating problems and delineate design tradeoffs between different prototype configurations.

\section{Test Setup and Data Collected}

Important fundamental vibrations of the wind turbine include natural bending modes of the tower and rotor components. The tower, nacelle, and rotor vibration modes may also interact or couple under certain conditions and cause an operational instability (6). Harmonic rotor loads that occur at multiples of the rotor speed can also excite the system's natural vibration modes. A fundamental system frequency that is driven by a harmonic rotor load is called a resonance condition. Potentially large structural displacements can result from a resonance condition. Therefore, operating at a critical rotor speed could be particularly damaging to the wind turbine system (7). An experimental fan plot, which shows natural system frequencies plotted against rotor speed, is an important DCT result (see Figure 1). The lines of constant slope (fanning out over the plot) are labeled from 1P (one-per-revolution) through 15P. Each fan line represents a harmonic order of the rotor speed. The measured natural system and component frequencies (F1 through F5) are shown on the ordinate axis of the fan plot. These natural frequencies may change with rotor speed.

The fan plot is used as a diagnostic tool. A resonance is observed in operating data as a large amplitude acceleration or load peak in the response spectra of the turbine (see Figure 2). The fan plot is used to highlight the rotor speeds at which harmonic rotor forces are likely to excite natural system frequencies, thereby causing large deflections known as a resonant condition. For example, the system frequency F1 in Figure 1 crosses the $1 \mathrm{P}$ harmonic at a rotor speed of 42 revolutions per minute (rpm), crosses the 2P harmonic at a rotor speed of $21 \mathrm{rpm}$, and crosses the $3 \mathrm{P}$ harmonic at a rotor speed of $14 \mathrm{rpm}$. Therefore, a resonant condition for frequency F1 could exist at a rotor speed of $42 \mathrm{rpm}$, forced by the rotor harmonic $1 \mathrm{P}$, or at a rotor speed of $21 \mathrm{rpm}$ excited by the rotor harmonic of $2 \mathrm{P}$, or at a rotor speed of $14 \mathrm{rpm}$ driven by the $3 \mathrm{P}$ rotor harmonic. On the other hand, whether a natural frequency is excited by a harmonic of rotor speed depends on several factors, including the wind turbine design and the amount of damping exhibited when the system is under load.

The rotor speed of a constant-speed wind turbine generator is usually chosen to avoid system frequencies that coincide with $1 \mathrm{P}$ and the first several per-revolution harmonics that are multiples of the number of rotor blades. For example, given a two-bladed machine, $2 \mathrm{P}, 4 \mathrm{P}, 6 \mathrm{P}$ and $8 \mathrm{P}$ rotor harmonics may have sufficient energy to excite a lightly damped system mode that occurs at the rotational frequency of the rotor. For a three-bladed rotor design, rotor harmonics of $3 \mathrm{P}, 6 \mathrm{P}, 9 \mathrm{P}$, and $12 \mathrm{P}$ have the potential to excite a fundamental system mode that coalesces with the operating speed of the rotor. For example, Figure 1 shows a vertical line representing the constant 36-rpm turbine operating speed. Given a two-bladed design and a moderately damped mode occurring at the frequency of F2 $(1.25 \mathrm{Hertz}[\mathrm{Hz}])$, the rotor harmonic $2 \mathrm{P}$ could have sufficient energy to force F2 even though Figure 1 indicates an interaction 
occurring at an operating speed of $37.5 \mathrm{rpm}$. Figure 1 also shows that a two-bladed rotor operating at 36 rpm could also experience an $8 \mathrm{P}$ rotor harmonic, forcing the system mode occurring at F5 (4.54 Hz). For a three-bladed design running at $36 \mathrm{rpm}$, Figure 1 indicates that the rotor harmonic of $3 \mathrm{P}$ could drive the system mode occurring at F3 $(1.83 \mathrm{~Hz})$.

We can readily appreciate that incorporating variable-speed technology presents a formidable challenge for the wind turbine designer. Because all rotors have some inherent imbalance, the 1P rotor harmonic can easily sweep through fundamental tower-bending frequencies of large wind turbine systems that use variable-speed technology. Looking at Figure 1, we see that over a typical rotor speed range of 15 to 45 $\mathrm{rpm}$, there are many opportunities for the rotor harmonics to interact with fundamental system frequencies. For a two-bladed, variable-speed turbine in particular, the 2P-rotor harmonic could excite several natural system frequencies; the 3P-rotor harmonic could also excite several system frequencies of a three-bladed, variable-speed turbine design. Advanced variable-speed controller designs use the measured system frequencies in a fan plot to identify critical rotor speeds that are likely to excite significant structural vibrations. These can be avoided by properly programming the wind turbine speed controller.

To identify a wind system's natural vibration frequencies and damping values, we conducted a series of parked rotor measurements. If the average ambient wind speed is low (less than $\sim 5 \mathrm{~m} / \mathrm{s}$ ), we made driving-point measurements on important structural components to obtain frequency response functions (FRF) (see Figure 3). A driving-point measurement is the collocation of a measured excitation force with a measured structural response. We can extract natural bending frequencies and damping values from FRF that are acquired from measurements made on the tower, drivetrain, and rotor blade. Figure 4 is a schematic of the instrumentation and shows the measurement locations we used to find the static (nonrotating) natural system frequencies of a typical three-bladed wind machine. We typically employ two different transient excitation techniques to measure frequency response functions. The first technique is a step-relaxation method developed by Carne (8) to test vertical-axis wind turbines. The fundamental bending frequencies of the wind turbine tower and drivetrain are fully excited and observed for the steprelaxation excitation method applied to the tower in low ambient wind conditions (see Figure 5). The second excitation technique involves applying an impulsive load to a wind turbine component with an instrumented impact hammer (9). Again under low ambient wind-speed conditions, impact testing is a convenient method to use on structural components that are lightly damped and have widely spaced modal frequencies, as shown in the FRF of Figure 3. We have found that impact testing is most useful in determining the flap and lag bending frequencies of the rotor blade as shown in Figure 6.

Higher ambient wind-speed conditions degrade driving point measurements due to unmeasured wind forces. Fortunately, the random wind forces that act on the wind turbine structure also excite the parked system modes of vibration (10). In addition, wind excitation has excellent low-frequency energy content, which is required to drive the low-frequency fundamental bending modes of the wind turbine tower and rotor blades. Figure 7 shows a power spectrum of fore-aft tower motion caused by wind excitation. The power spectrum was computed for the rotor-parked condition so the peaks in the spectra represent natural frequencies of the system. However, we cannot directly extract damping values and other scaled modal properties of the wind turbine structure from wind excitation spectra alone, as we can with the FRF measurements. The ability to measure fundamental system frequencies using the methods mentioned above gives us the flexibility to work with uncontrollable ambient wind conditions. Therefore, under most field test situations, we can at least obtain the fundamental component and natural system frequencies of a parked wind turbine.

To measure natural vibrations of the drivetrain at the low-speed shaft, we used piezo-resistive, three-axis (triaxial) accelerometers (see Figure 8). One axis of the triaxial accelerometer is aligned along the lowspeed shaft (LSS) to measure motion along the thrust axis of the turbine. The second axis is 
perpendicular to the LSS and measures the motion of the drivetrain in the nacelle's yaw direction. The third axis of the triaxial accelerometer is also aligned perpendicular to the LSS and measures motions of the drivetrain that represent pitching of the nacelle. To measure the natural bending motion of the tower, we used high quality, inertial-grade, dual-axis (biaxial) accelerometers (see Figure 9). One axis of the biaxial accelerometer is aligned to measure fore-aft motion of the tower; the second axis is aligned to measure side-to-side tower motion. Both types of transducers have the high sensitivity and good lowfrequency characteristics that are necessary to discriminate between the tower's fundamental bending modes and the rotor's natural bending frequencies.

We measured the wind system's operating steady-state dynamic response in terms of the motions or accelerations that the structure experienced over a 10-minute period while running at rated or above conditions. The wind turbine's steady-state response is described by computing the power spectra of the drivetrain's accelerations measured at the hub bearing (shown in Figure 2). We also characterized steadystate operation by calculating the power spectra of tower motions measured below the yaw bearing (see Figure 10). Other measurement locations of interest include tower or drivetrain components that exhibit excessive vibration during normal operation.

The steady-state vibration spectra are correlated with the turbine's power-performance data that is simultaneously collected during each 10-minute record. Table 1 is a list of typical test signals that are collected during a dynamic characterization test. Table 1 includes the turbine's power-performance parameters and additional tower response signals that were collected to help an industry partner compare tower designs. When possible, we obtain the wind turbine's power-performance parameters, such as wind speed and electrical power generated directly from the wind turbine's controller or powerperformance metering instrumentation. Figure 11 shows a schematic of the data acquisition system we use to collect dynamic response and power-performance signals for a typical dynamic characterization test. In some instances, the system's performance signals are not readily available from the wind turbine's controller. In that case, we install a standard suite of performance instrumentation that we use for power and performance certification testing (11). The table includes some additional drivetrain and tower acceleration signals that were collected for a particular field test with an industry partner.

We collect time series of peak accelerations during operational events such as startup (Figure 12a), normal shutdown (Figure 12b), loss of line fault (Figure 12c), and emergency shutdown (Figure 12d) to describe of the wind system's transient response. The structural degrees of freedom we choose to make acceleration measurements for both steady-state and transient dynamic response are located on components that transfer load from the rotor to the drivetrain and between the nacelle and tower. We measure operating accelerations parallel and perpendicular to the thrust axis of the rotor with the same triaxial accelerometer on the low-speed shaft bearing (Figure 8) that was used to measure the natural frequencies of the parked rotor system. We also measure operating fore-aft and side-to-side tower motions with the same biaxial accelerometer (Figure 9) that was used to measure the parked-rotor fundamental tower bending frequencies.

We can identify system modes, such as tower bending coupling with rigid-body drivetrain motion, by computing cross spectra of acceleration signals and analyzing the relative phase between the signals. Using cross-power analysis of relative motion between components also helps us understand the forced response or operating deflections experienced by the system under load. For example, by comparing the phase between hub and generator motion for frequency peaks in the component's cross spectra, we can determine which component is leading (or lagging) and is thereby responsible for the forced motion (see Figures $13 \mathrm{a}$ and $13 \mathrm{~b}$ ). We have also measured the relative flexibility between rotor and tower bending modes to help researchers find better stiffness values for input into a dynamic wind-system simulation model (12). Accurately modeling the rotor modes that couple with tower bending modes through the 
drivetrain is important to help us understand how some operating instabilities can cause premature fatigue of the drivetrain and of its attachment hardware to the tower top.

We correlate the acceleration measurements from the nacelle and tower with critical speeds of the rotor to identify resonant conditions. This is accomplished by collecting operating accelerations simultaneously with the azimuth position and rotor speed. A combination of Hall-effect switch and magnetic pickup are used to measure the azimuth position and speed of the LSS (see Figure 14). Component vibration data plotted against changing rotor speed is called a waterfall diagram. A waterfall diagram is shown in Figure 15 for a turbine coasting down from a rated rotor speed of $35 \mathrm{rpm}$ to $9 \mathrm{rpm}$. Peaks in the waterfall diagram are system frequencies excited by harmonic forces as the speed of the rotor changes. In Figure 15 , four driven-system frequencies are highlighted as slices of the waterfall diagram. The first two slices of 0.6875 and $0.7817 \mathrm{~Hz}$ are fundamental bending modes of the tower. The second two slices of 1.688 and $1.781 \mathrm{~Hz}$ are rotor-nacelle modes of vibration, possibly coupling with higher bending modes of the tower. Looking at the upper plot of Figure 15, we see that the system mode occurring at $1.781 \mathrm{~Hz}$ achieves a peak acceleration of 16 milli-G's (mG). In addition, the system modes occurring at 1.688 , 0.7813 , and $0.6875 \mathrm{~Hz}$ attain peak accelerations of $12 \mathrm{mG}$. Initially, these may seem to be low acceleration levels for the system modes excited by harmonics rotor forces. However, the acceleration data should be analyzed in terms of peak displacement for each of the system frequencies excited. For sinusoidal response, the peak displacement is proportional to the peak acceleration divided by the square of the frequency at which it occurs. Table 2 lists computed peak displacement values for the system modes highlighted in Figure 15. From Table 2, we can see that the fundamental tower mode of vibration has nearly five times the displacement occurring at $0.6875 \mathrm{~Hz}$ as does the rotor-nacelle mode occurring at $1.781 \mathrm{~Hz}$ for nearly the same acceleration level.

\section{Future Work}

As mentioned earlier, we collect a 10-minute time series record of operating accelerations for the wind machine running at rated or above conditions. The 10-minute record is used to characterize the wind system's steady-state response. However, a recent study has identified diurnal variation as an important factor in evaluating turbulence-induced wind turbine loads (13). Therefore, the time of day during which the 10-minute time series record is collected must be considered when characterizing peak operating conditions of the wind machine. So far, we have collected operating data that were available during intensive field test programs that have lasted little more than a week. The data acquisition system (DAS) shown in Figure 11 is capable of collecting several hours to a couple of days worth of operating data, depending on the sample rate. However, the DAS in Figure 11 is not automated and is dependent on an operator who decides when, what, and how many data are to be collected.

To better characterize the overall operating dynamics of a wind machine, long-term data are needed over a full wind season. Our next generation DAS has been designed such that the wind system's power performance information is logged with the turbine's structural response data. Specifically, the long term data collection system looks like the DAS in Figure 11 with the HP front-end, PC-controller, and mass storage systems replaced with a multi-channel data logger. The data logger is programmed to collect dynamic response data in conjunction with the wind machine's power performance data. The data are vibration statistics stored in a test matrix that is programmed into the data logger. The independent portion of the of the test matrix is partitioned into inflow conditions (14) that reflect the time of day or diurnal variations of the turbine's operating environment. The dependent portion of the test matrix is partitioned in terms of the wind machine's performance, including power production level for a constantspeed turbine or as a function of operating speed for a variable-speed wind turbine. The information collected with the long-term DAS supplements the fundamental natural frequencies and transient operating data collected during the intensive data-collection portion of a dynamic characterization test. 


\section{Acknowledgements}

The author thanks Grant McFarland of Mountain Valley Energy for helping design and fabricate the data acquisition system that we used in the dynamic characterization tests. Grant was also instrumental in supporting the field tests by installing the vibration sensors and maintaining the DAS. The author also thanks Eric Jacobson of NREL's Certification Team for providing his expertise in setting up the suite of instrumentation used to make the power-performance measurements on the turbines tested. Eric's support in helping us to set up the dynamic characterization tests was also invaluable in our effort to complete all the tests in a timely manner.

\section{References}

1. Vachon, W.A. Control Algorithms for Effective Operation of Variable Speed Wind Turbines. SAND90-7112, UC-261, October 1993.

2. Draft IEC 61400-22. Wind Turbine Generator Systems Section 8: Type Certification. TC88, 199812-18.

3. NWTC Certification Team. General Quality Manual. GP01-98268.

4. Osgood, R.M. Zond Z-40M Dynamic Effects Test. Internal Contractor Report, October 1998.

5. Wright A.D. Validation of a Model for a Two-Bladed Flexible Rotor System. NREL/CP-500-25514, November 1998.

6. Bir, G.S. "Modal Dynamics of Next Generation Flexible-Rotor and Soft-Tower Wind Turbine," Fifteenth International Modal Analysis Conference, Orlando FL, 1997.

7. Osgood, R.M. Modal Testing of Advanced Wind Turbine Systems. NREL/CP-500-7387, November 1998.

8. Carne, T.G. Modal Testing in the Design Evaluation of Wind Turbines. SAND87-2461, UC-60, April 1988.

9. Brown, D.L. "Impulse Technique for Structural Frequency Response Testing," Sound and Vibration. November 1977, pp. 8-21.

10. James, G.H. "Extraction of Modal Parameters from Operating HAWT using the Natural Excitation Technique (NeXT)." Proceedings of the 1994 ASME Wind Energy Symposium, Wind Energy -1994. SED-Vol. 15, New York, ASME, 1994; pp. 227-232.

11. Wright, A.D., Osgood, R.M., Malcolm, D.J. "Analysis of a Two-bladed, Teetering-Hub Turbine Using the ADAMS Software.” Prepared for Windpower '94, Minneapolis, MN, May 1994.

12. IEC. Wind Turbine Generator Systems Part 12: Wind Turbine Power Performance Testing. IEC 61400-12, 1998-02.

13. Kelley, N.D. "A Case for Including Atmospheric Thermodynamic Variables in Wind Turbine Fatigue Loading Parameter Identification." NREL/CP-500-26829, July 1999. Prepared for the Second Symposium on Wind Conditions for Wind Turbine Design, IEA Annex XI, Roskilde, Denmark, April 12-13, 1999.

14. Kelley, N.D. Identification of Inflow Fluid Dynamics Parameters That Can Be Used to Scale Fatigue Loading Spectra of Wind Turbine Structural Components. Musial, W.D.; Hock, S.M.; Berg, D.E., 
eds. Wind Energy 1994: Proceedings of the Energy-Sources Technology Conference, 23-26 January 1994, New Orleans, Louisiana. SED-Vol. 15. New York: American Society of Mechanical Engineers, 1994; pp. 181-188. Acc No. 14967. 
Table 1. Typical Signals Collected for a Dynamic Characterization Test

\begin{tabular}{|c|c|c|c|c|}
\hline DAS & Data Channel Descriptor & Sensor & Serial & Signal \\
\hline Chnl & Measured Parameter & Type & \# & Sensitivity \\
\hline 1 & LSS Azimuth position (1 per-rev pulse) & Mag-pickup & MSC427 & 0 to $5 \mathrm{v}$-peak \\
\hline 2 & Generator speed (rpm) & Controller Sensor & $\mathrm{N} / \mathrm{A}$ & $2 \mathrm{mV} / \mathrm{rpm}$ \\
\hline 3 & Generator Power (kW) & Controller Sensor & $\mathrm{N} / \mathrm{A}$ & $3.79 \mathrm{mV} / \mathrm{kW}$ \\
\hline 4 & Wind Speed $(\mathrm{m} / \mathrm{s})$ & Climatronix Cup & 3546 & $1.726 \mathrm{mV} / \mathrm{m} / \mathrm{s}$ \\
\hline 5 & Hub-bearing fore-aft acceleration (G) & Endevco 2262A & L11955 & $3.45 \mathrm{~V} / \mathrm{G}$ \\
\hline 6 & Hub-bearing lateral (yaw) acceleration (G) & Endevco 2262A & L12050 & $2.733 \mathrm{~V} / \mathrm{G}$ \\
\hline 7 & Hub-bearing pitch acceleration $(\mathrm{G})$ & Endevco 2262A & L11778 & $3.365 \mathrm{~V} / \mathrm{G}$ \\
\hline 8 & Generator fore-aft acceleration & Endevco 2262C & $\mathrm{HD} 86 \mathrm{H}$ & $1.637 \mathrm{~V} / \mathrm{G}$ \\
\hline 9 & Generator lateral (yaw) acceleration (G) & Endevco 2262C & GF73G & $1.615 \mathrm{~V} / \mathrm{G}$ \\
\hline 10 & Generator pitch acceleration $(\mathrm{G})$ & Endevco 2262C & GT58H & $2.037 \mathrm{~V} / \mathrm{G}$ \\
\hline 11 & Tower top corner \#1 fore-aft acceleration (G) & Force Balance & 45895 & $1000 \mathrm{mV} / \mathrm{G}$ \\
\hline 12 & Tower top corner \#1 lateral acceleration (G) & Force Balance & 47914 & $1000 \mathrm{mV} / \mathrm{G}$ \\
\hline 13 & Tower X-brace fore-aft acceleration (G) & Force Balance & 47890 & $1000 \mathrm{mV} / \mathrm{G}$ \\
\hline 14 & Tower X-brace lateral acceleration (G) & Force Balance & 45886 & $1000 \mathrm{mV} / \mathrm{G}$ \\
\hline 15 & Tower leg \#1 fore-aft acceleration (G) & Force Balance & 45896 & $500 \mathrm{mV} / \mathrm{G}$ \\
\hline 16 & Tower leg \#1 lateral acceleration (G) & Force Balance & 47915 & $500 \mathrm{mV} / \mathrm{G}$ \\
\hline
\end{tabular}

Table 2. Peak Displacements for Frequency Slices of Waterfall Diagram

\begin{tabular}{|c|c|c|c|}
\hline Frequency Slice, $\mathbf{f}$ & Acceleration, $\mathbf{A}$ & Radial Frequency, & Displacement, D \\
\hline $\mathbf{H z}$ & $\mathbf{m G}$ & $\mathbf{r a d} / \mathbf{s e c}$ & $\mathbf{m m}$ \\
\hline 0.6875 & 12 & 4.32 & 6.31 \\
\hline 0.7813 & 12 & 4.91 & 4.88 \\
\hline 1.688 & 12 & 10.61 & 1.05 \\
\hline 1.781 & 16 & 11.19 & 1.25 \\
\hline
\end{tabular}




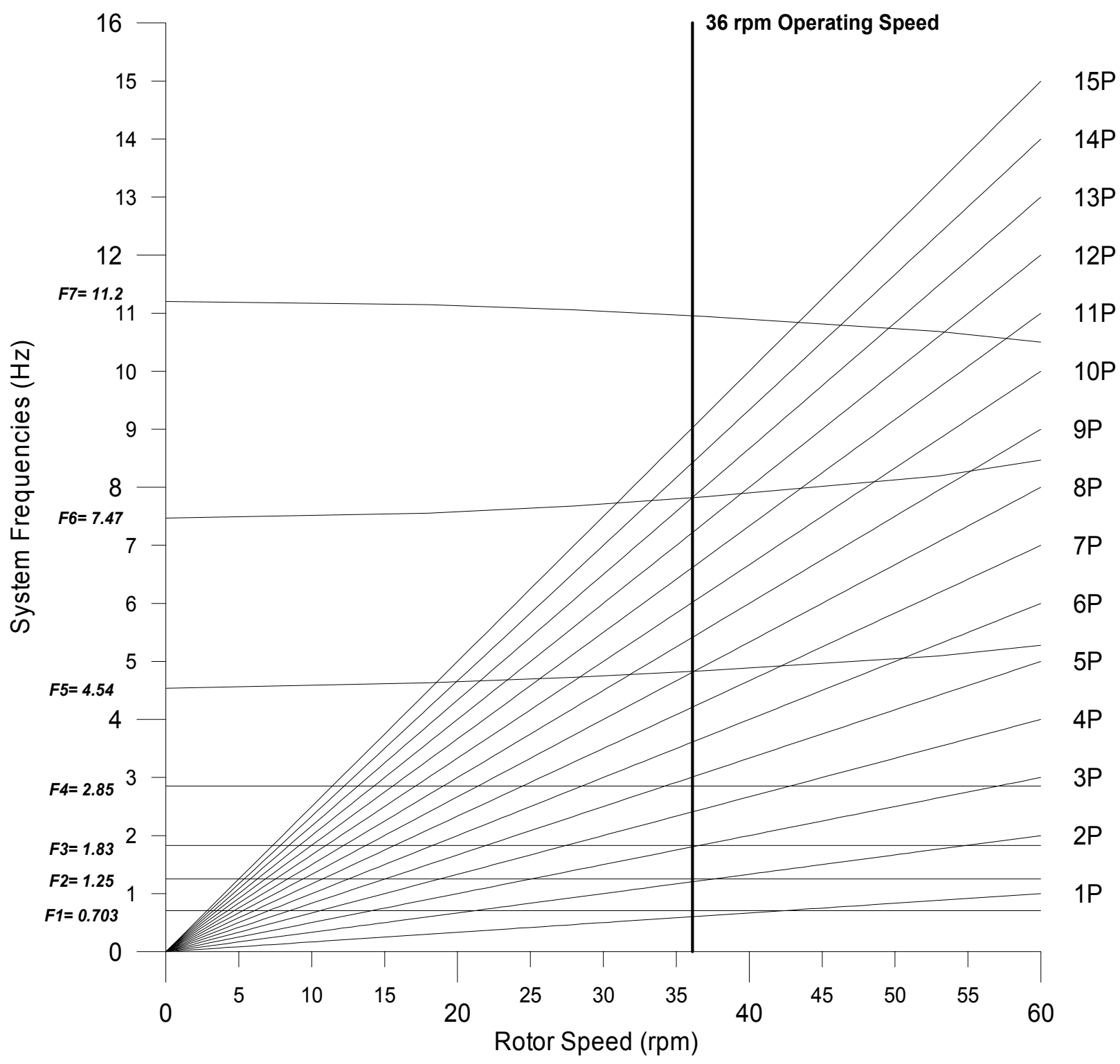

Figure 1. Typical fan plot of wind turbine natural frequencies 


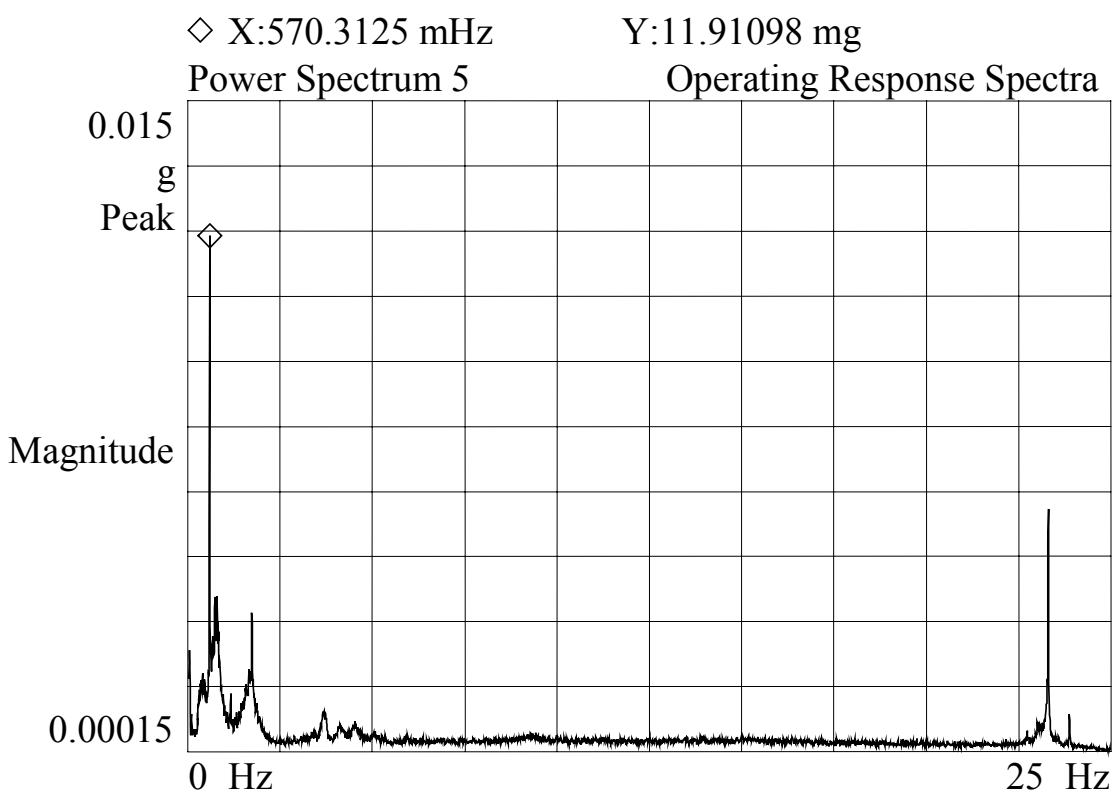

Figure 2. Operating spectra of hub bearing fore-aft acceleration

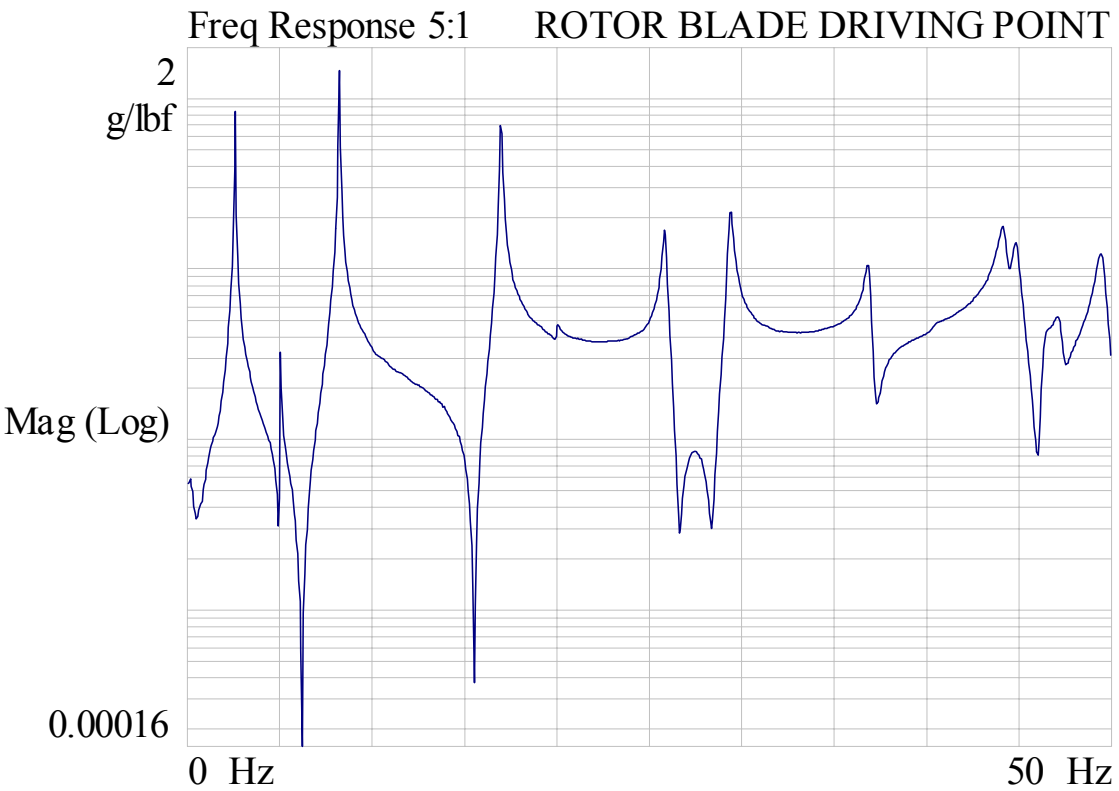

Figure 3. Rotor blade driving point frequency response function 

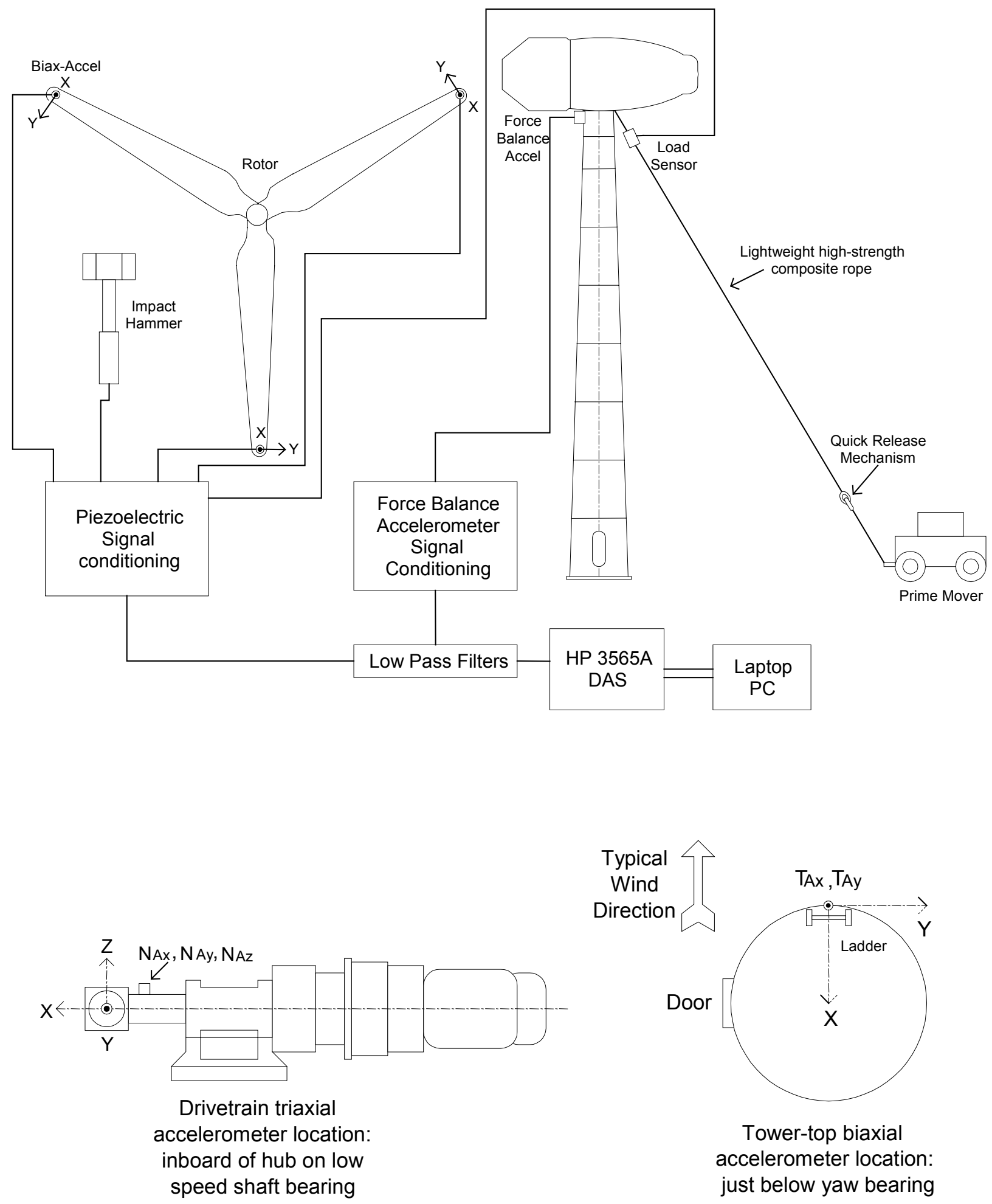

Figure 4. Equipment schematic and sensor locations used to measure non-rotating natural system frequencies. 


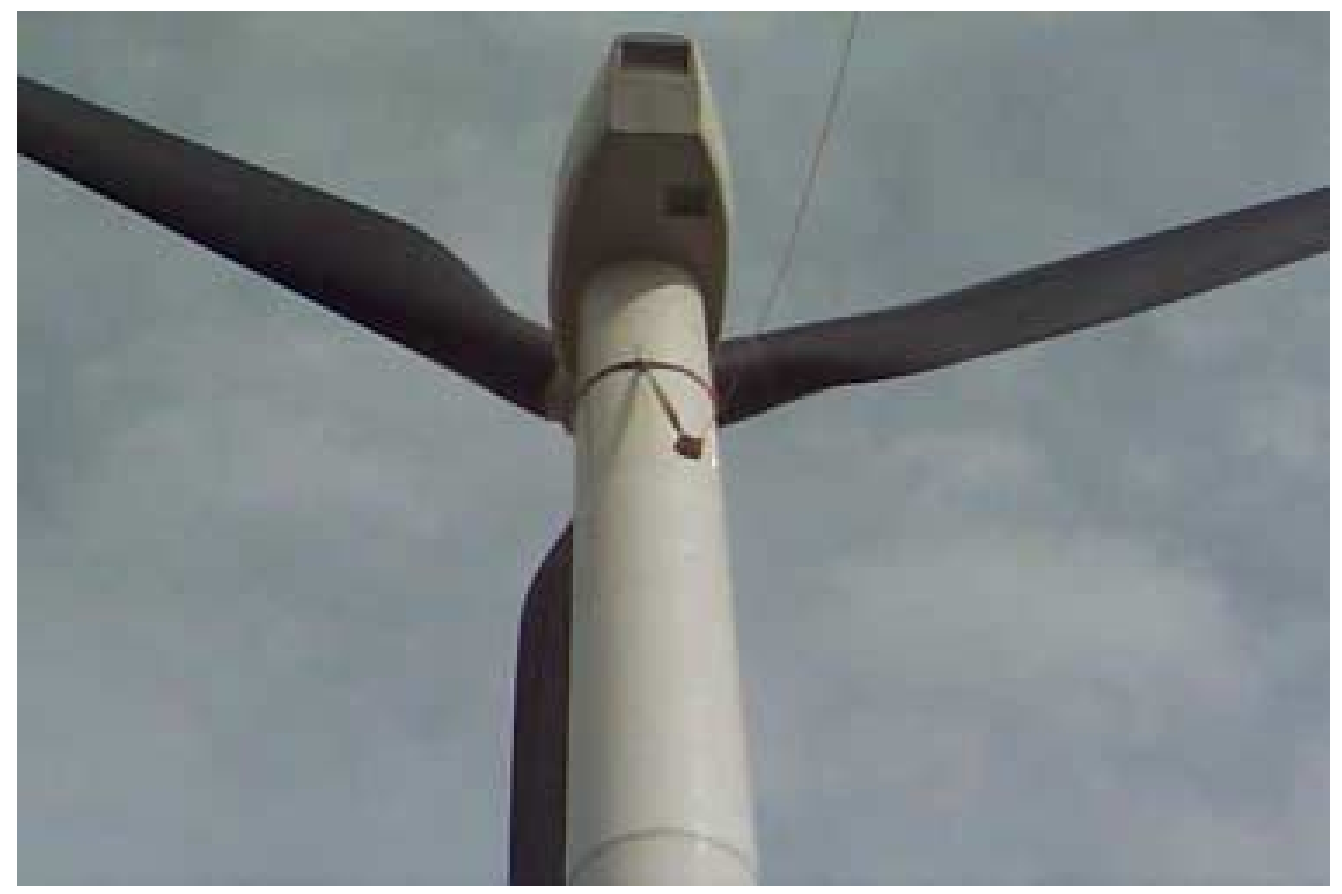

Figure 5. Step-relaxation load method applied to tower

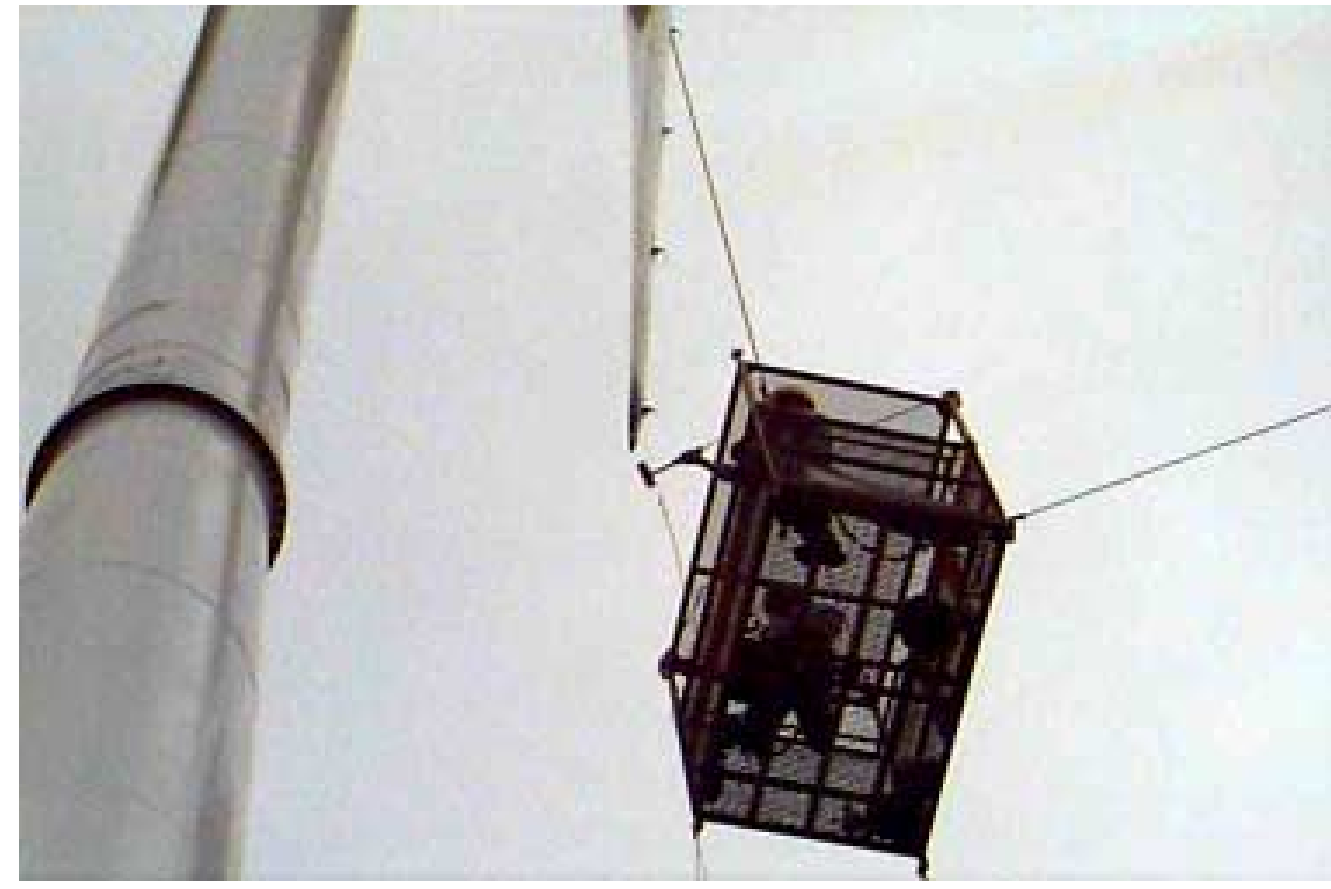

Figure 6. Driving point measurement using impact excitation technique 


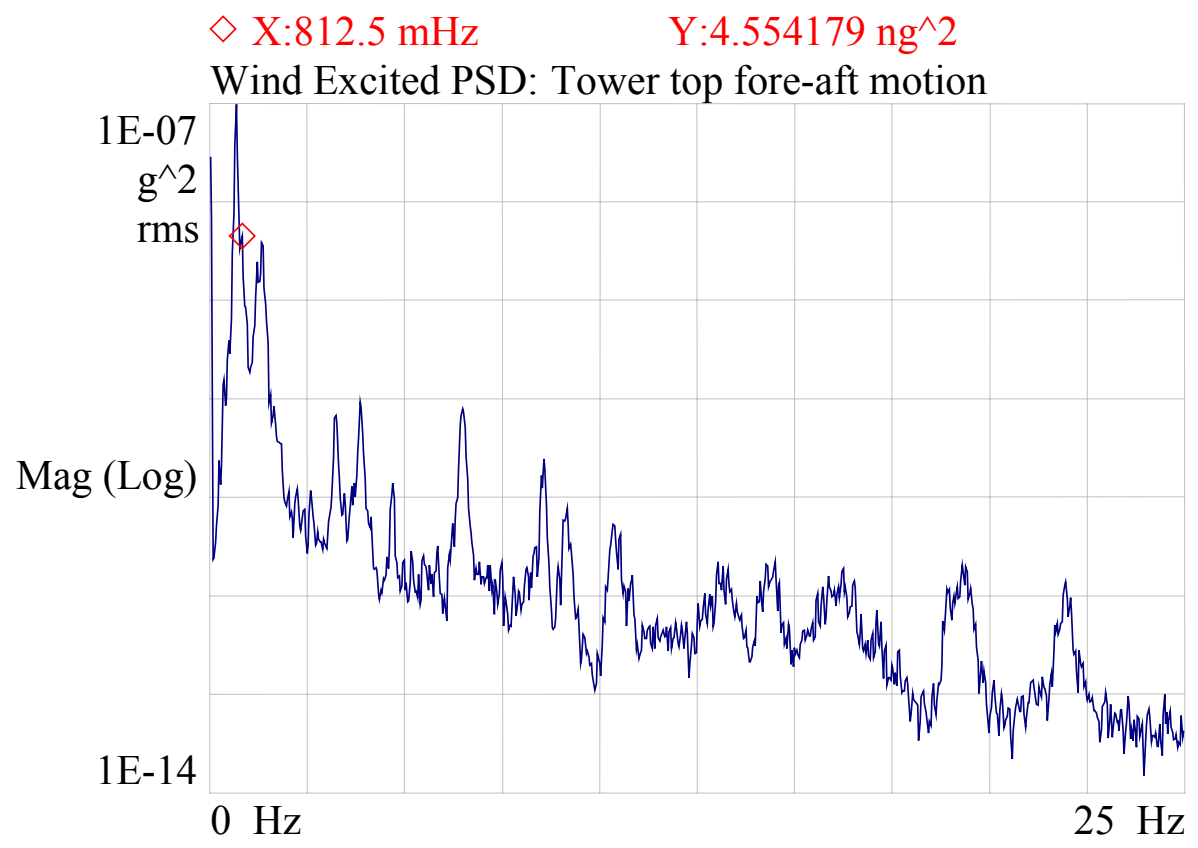

Figure 7. Power spectra of tower fore-aft motion due to wind excitation

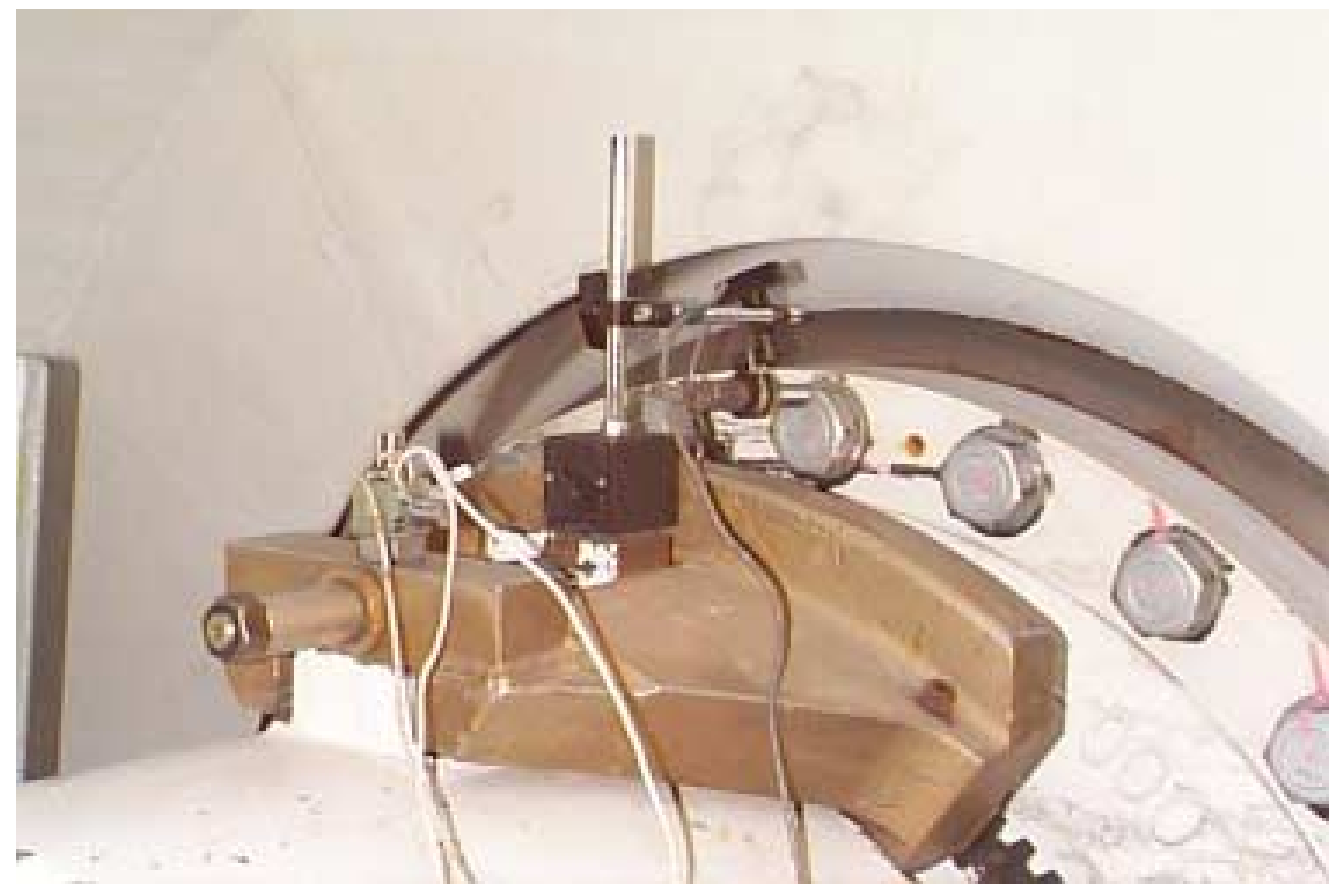

Figure 8. Triaxial accelerometer sensor on low-speed shaft bearing 


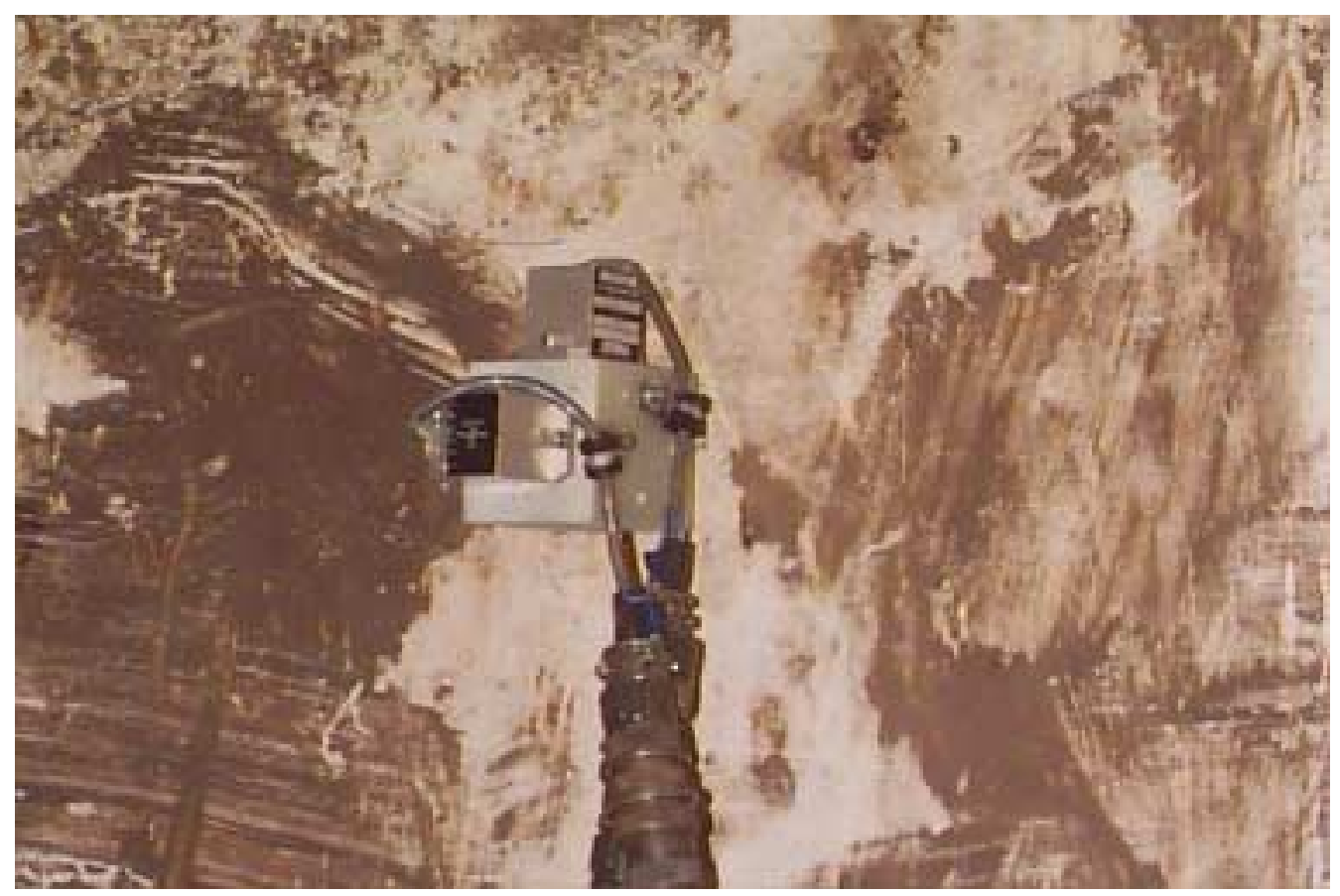

Figure 9. Biaxial accelerometer mounted inside tower below yaw bearing

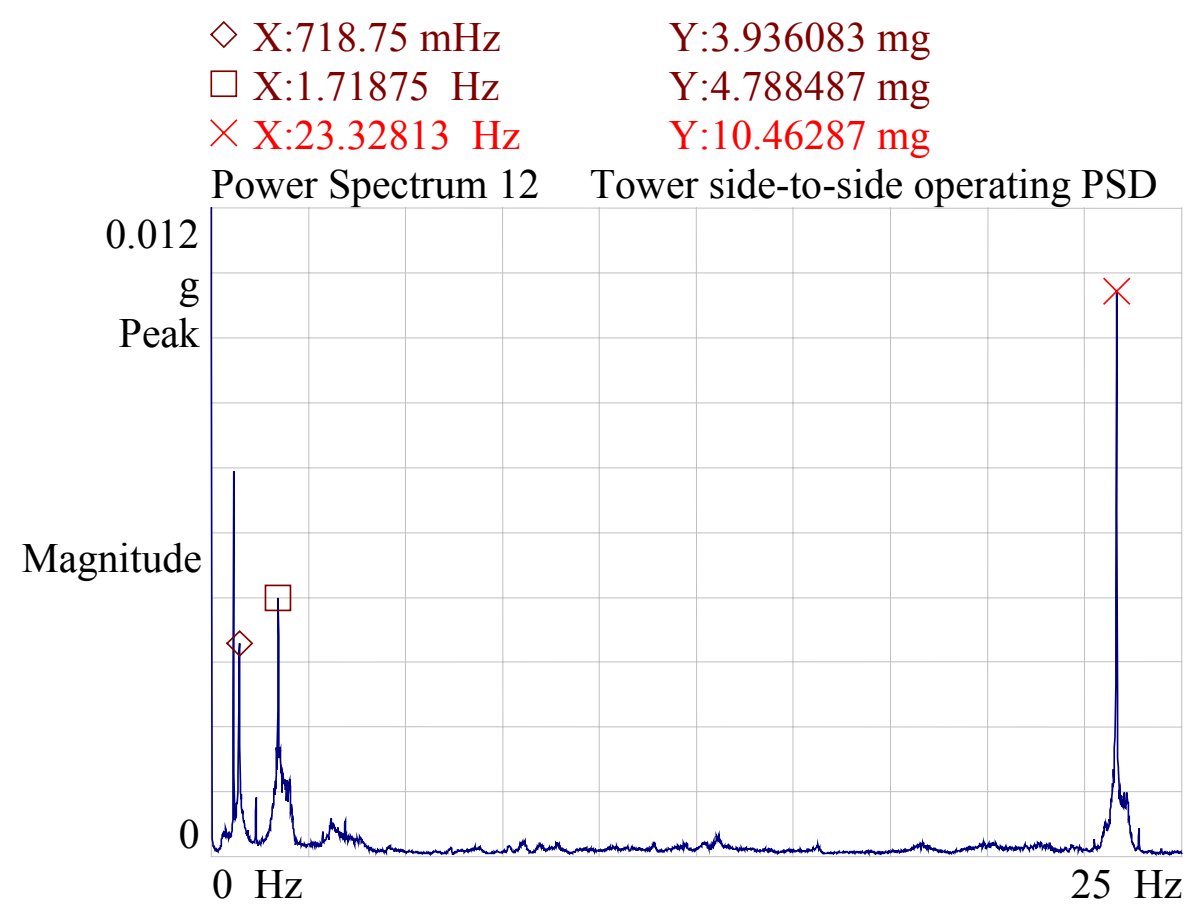

Figure 10. Operating spectra of tower side-to-side motion 
Intensive Data Collection Equipment Block Diagram for Dynamic Characterization Testing.

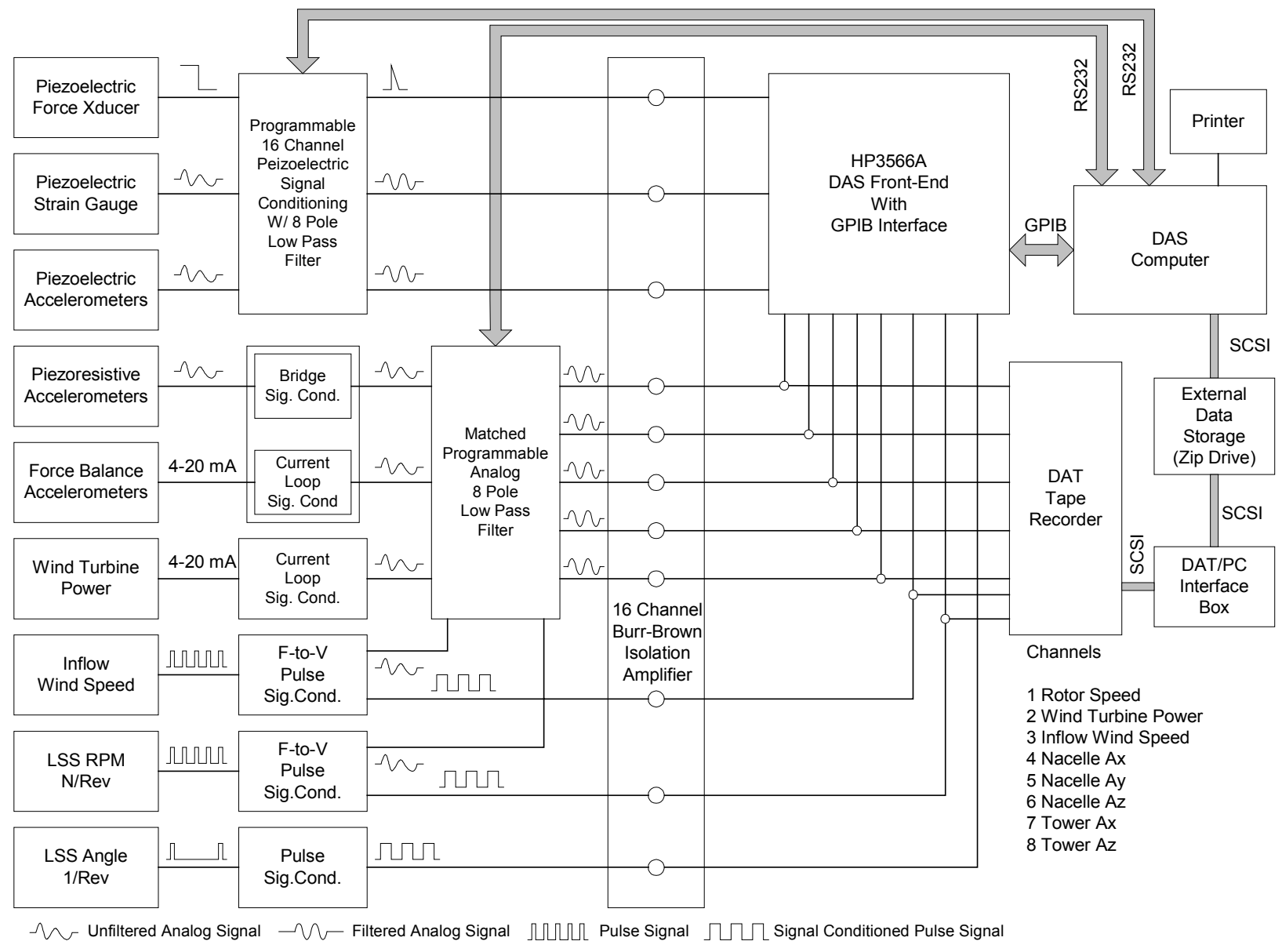

Figure 11. Data acquisition system used to collect dynamic response and power performance signals 


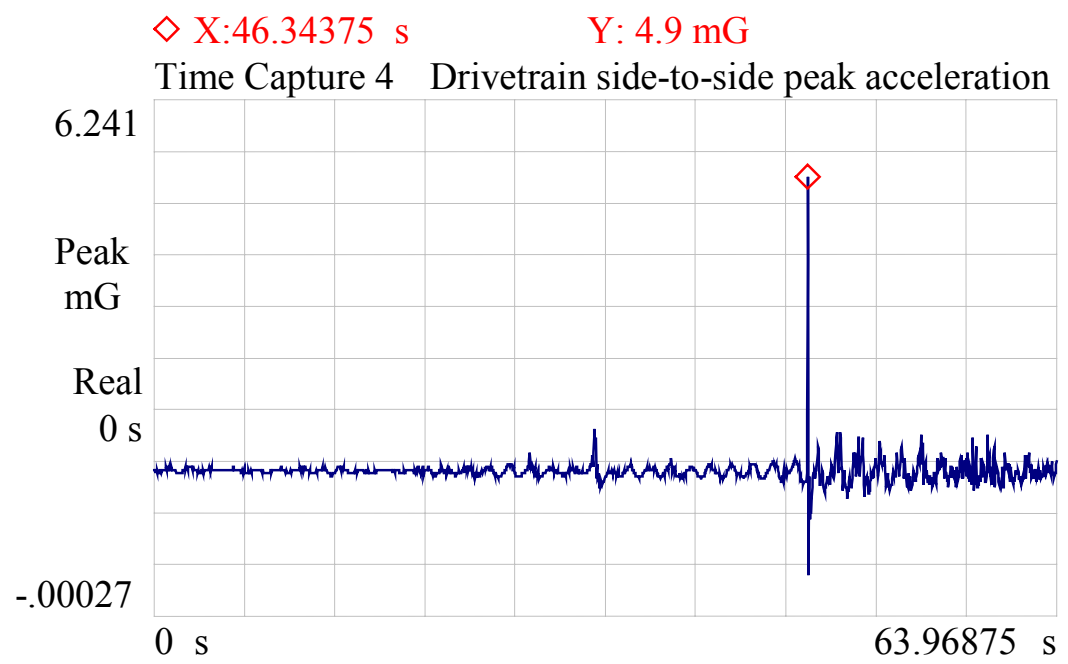

Figure 12a. Drivetrain side-to-side peak acceleration during start-up

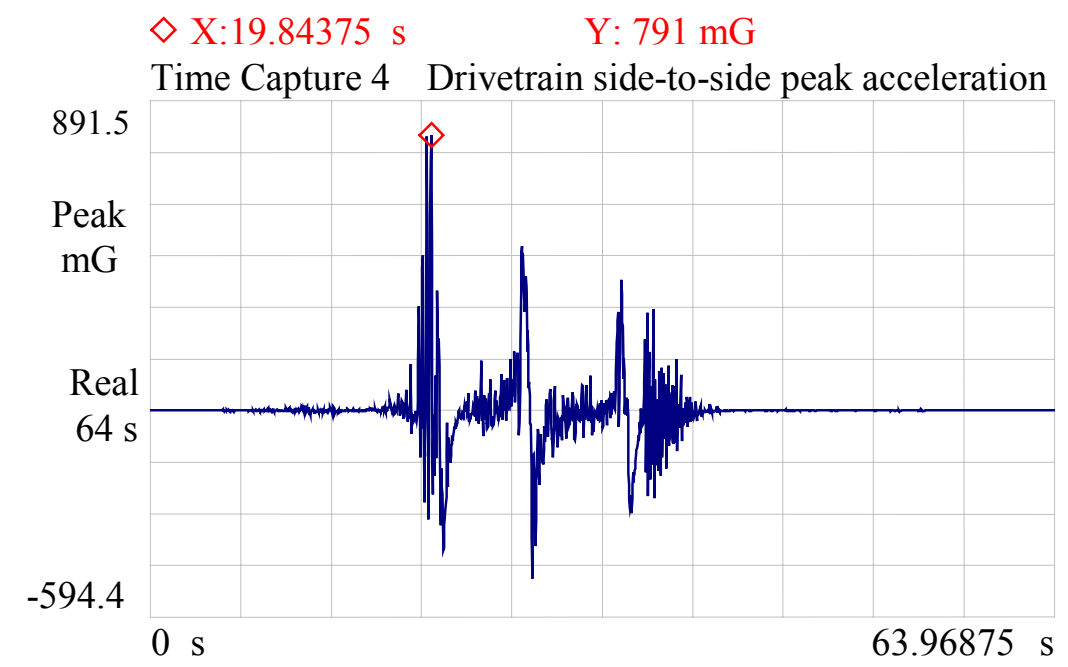

Figure 12b. Drivetrain side-to-side peak acceleration during normal shutdown 


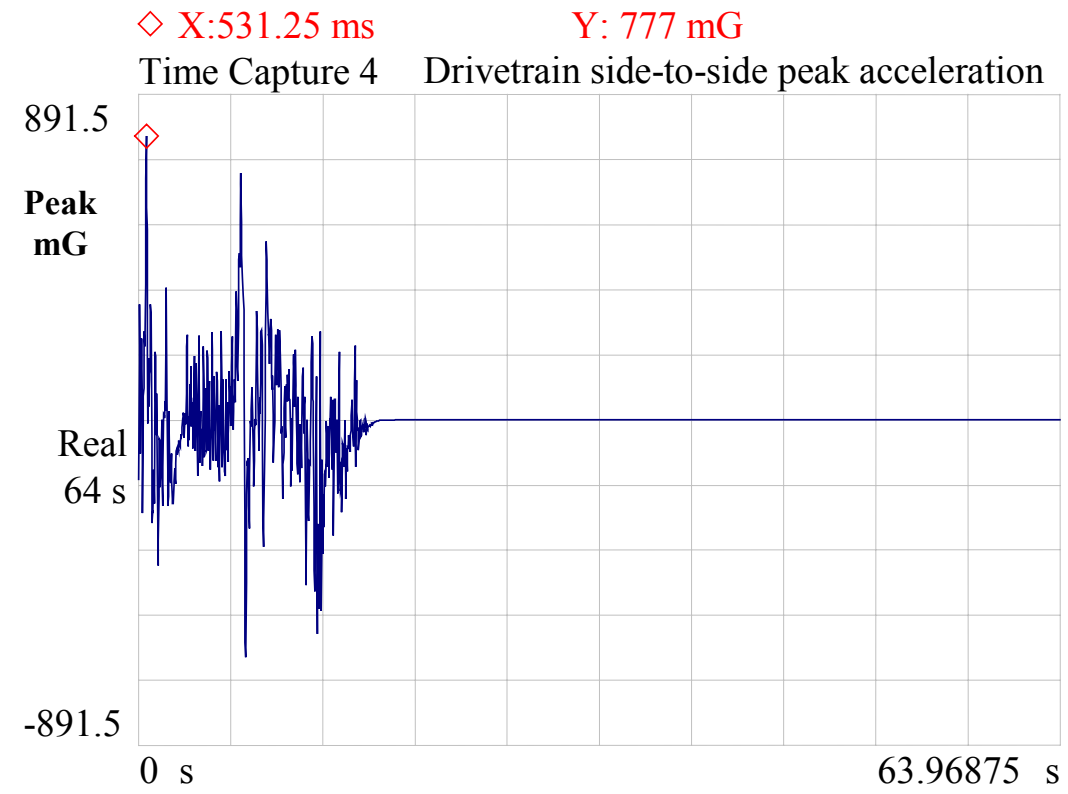

Figure 12c. Drivetrain side-to-side peak acceleration during loss-of-line event

$\diamond \mathrm{X}: 7.5 \mathrm{~s} \quad \mathrm{Y}: 1,310 \mathrm{mG}$

Time Capture 4 Drivetrain side-to-side peak acceleration

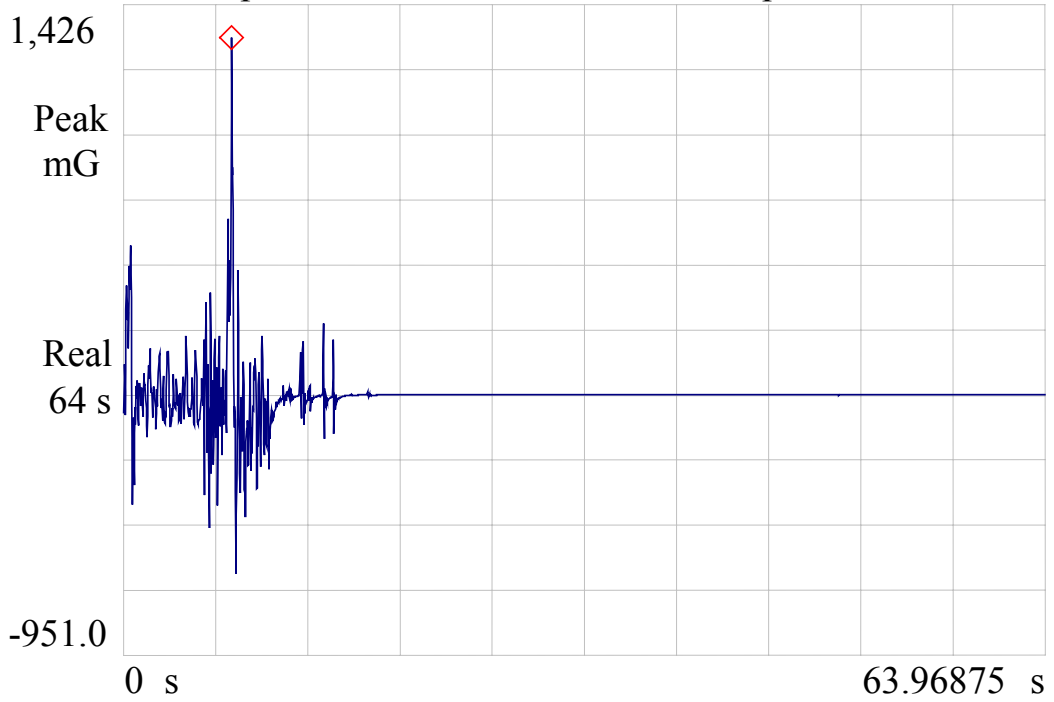

Figure 12d. Drivetrain side-to-side peak acceleration during emergency stop 


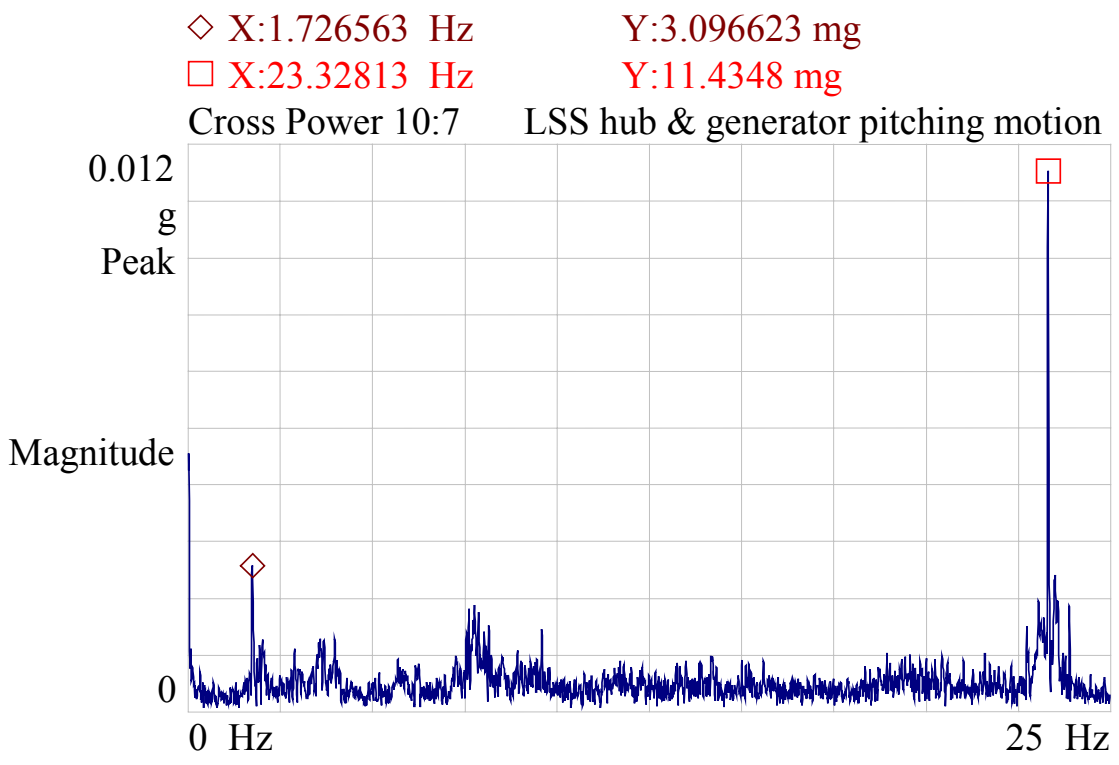

Figure 13a. Magnitude cross spectra between LSS hub and generator pitch motion

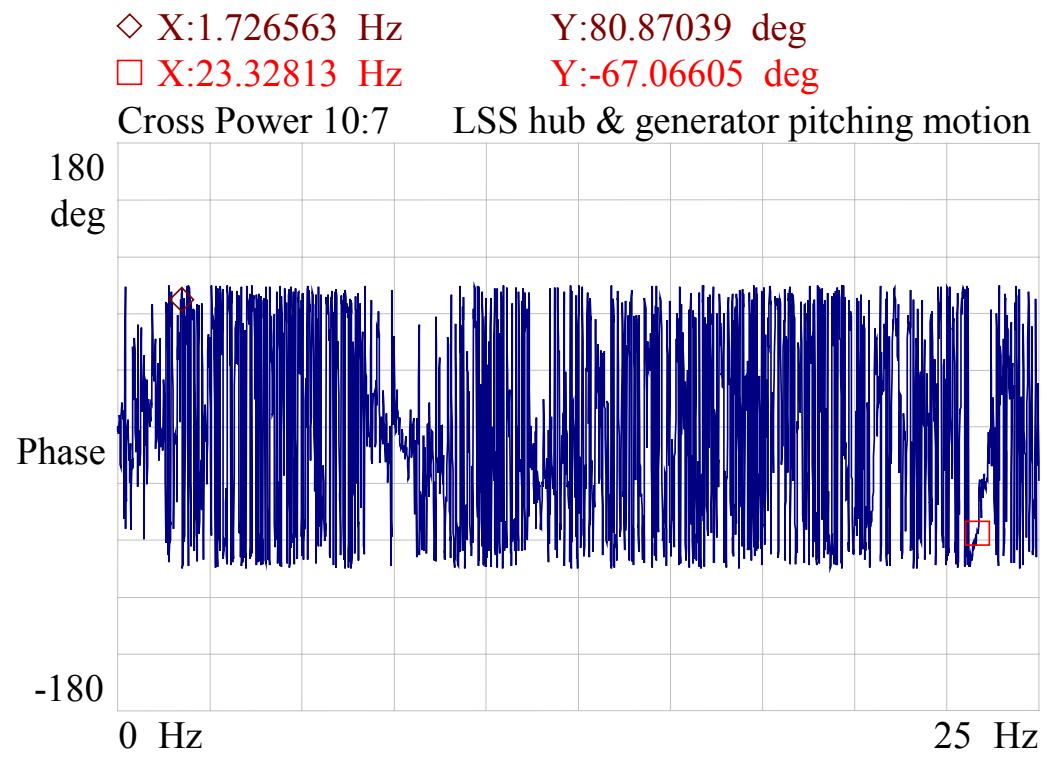

Figure 13b. Phase cross spectra between LSS hub and generator pitch motion 


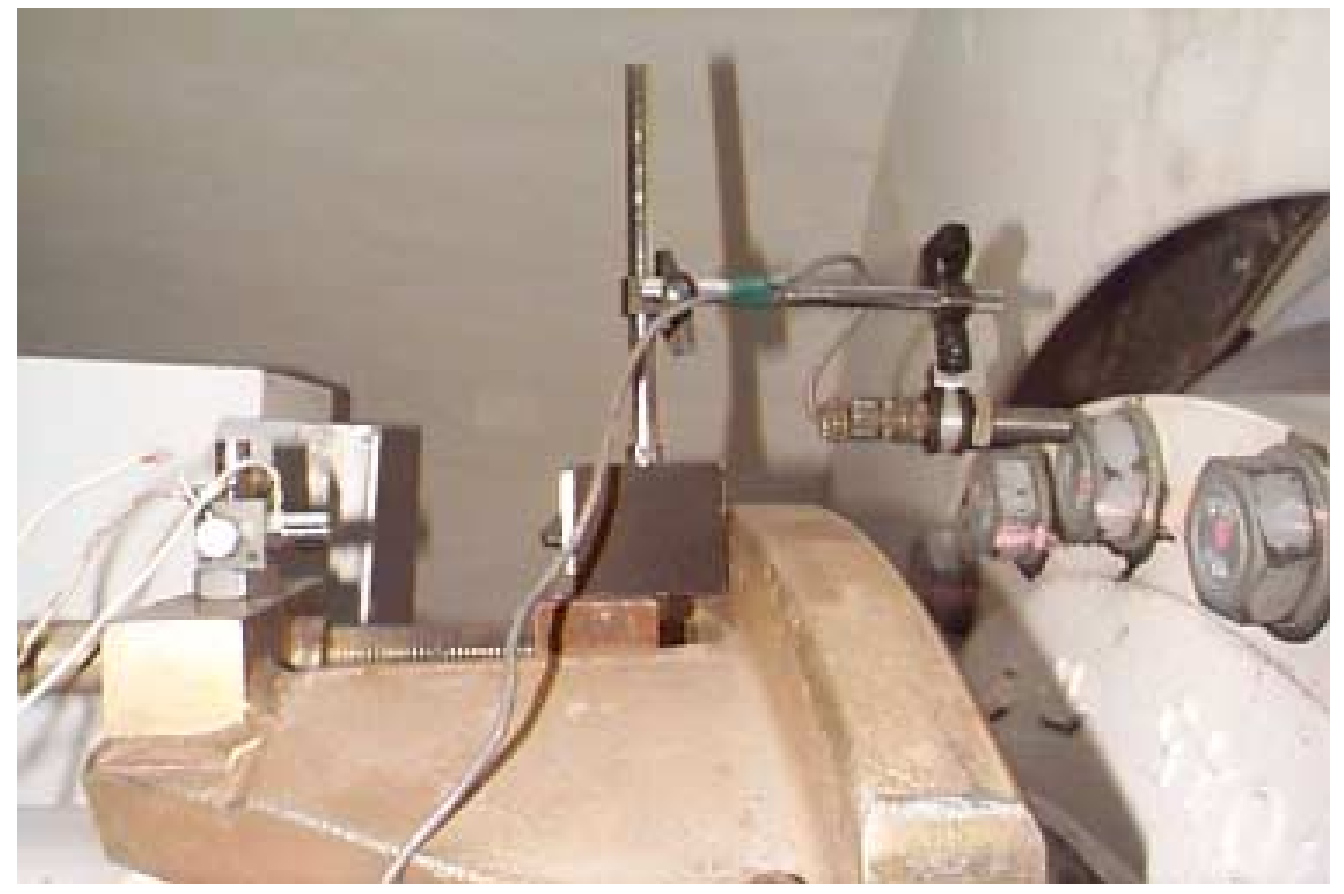

Figure 14. Rotor azimuth position and low-speed shaft sensors

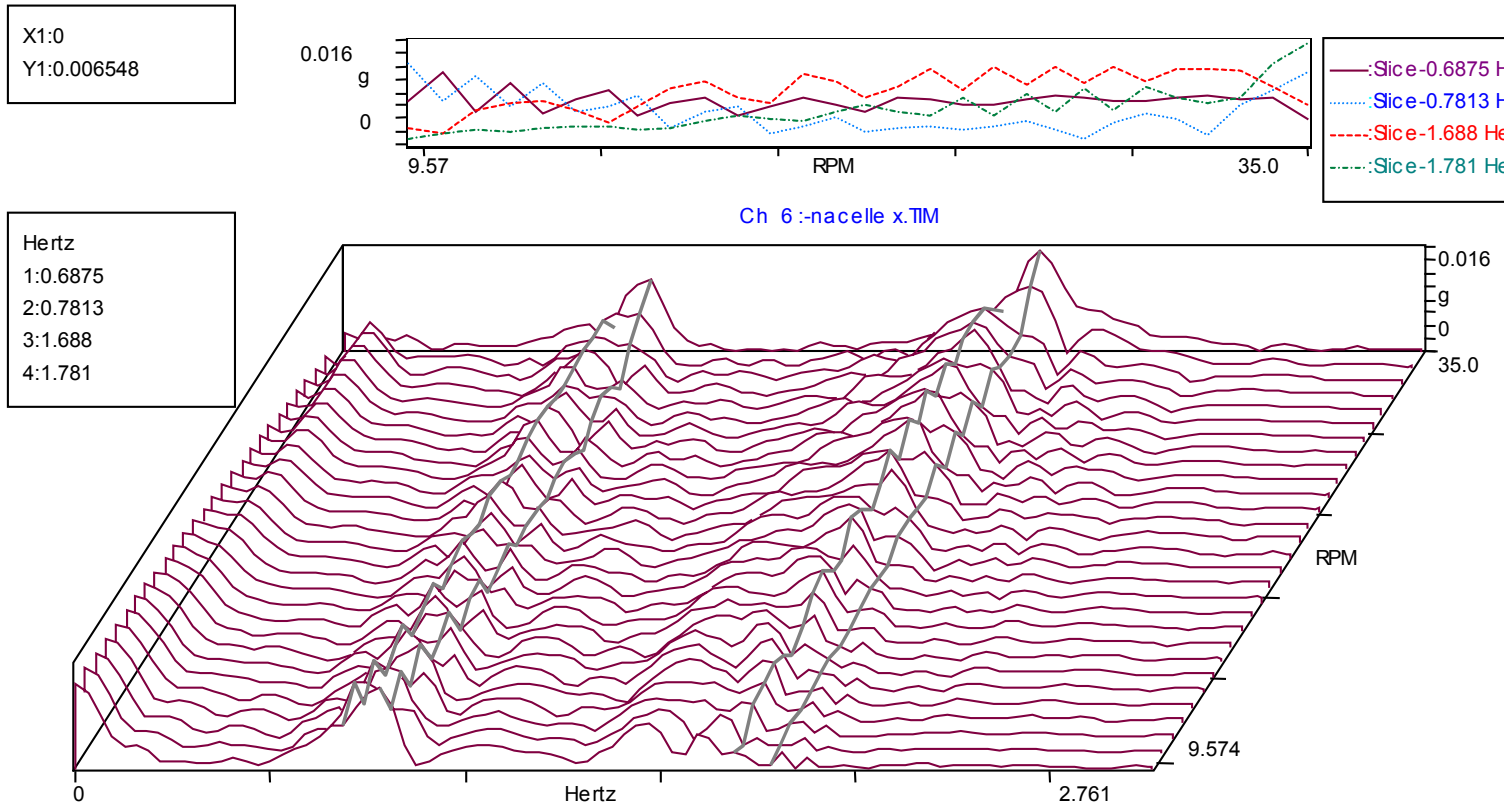

Figure 15. Waterfall diagram of wind turbine during coast down 


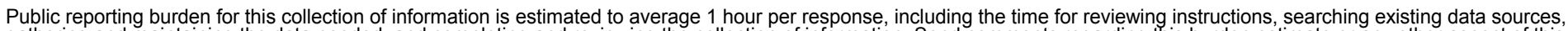

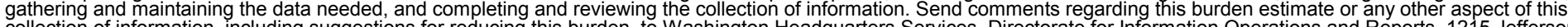

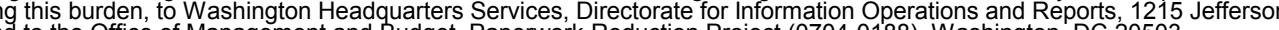
Davis Highway, Suite 1204, Arlington, VA 22202-4302, and to the Office of Management and Budget, Paperwork Reduction Project (0704-0188), Washington, DC 20503.
1. AGENCY USE ONLY (Leave blank)
2. REPORT DATE
May 2001
3. REPORT TYPE AND DATES COVERED Technical Report

4. TITLE AND SUBTITLE

Dynamic Characterization Testing of Wind Turbines

6. $\mathrm{AUTHOR}(\mathrm{S})$

Richard M. Osgood

7. PERFORMING ORGANIZATION NAME(S) AND ADDRESS(ES)
5. FUNDING NUMBERS

WER1.3010

8. PERFORMING ORGANIZATION REPORT NUMBER NREL/TP-500-30070

10. SPONSORING/MONITORING AGENCY REPORT NUMBER

9. SPONSORING/MONITORING AGENCY NAME(S) AND ADDRESS(ES)

National Renewable Energy Laboratory

1617 Cole Blvd.

Golden, CO 80401-3393

11. SUPPLEMENTARY NOTES

NREL Technical Monitor: NA

12a. DISTRIBUTION/AVAILABILITY STATEMENT

National Technical Information Service

12b. DISTRIBUTION CODE

U.S. Department of Commerce

5285 Port Royal Road

Springfield, VA 22161

13. ABSTRACT (Maximum 200 words)

The U.S. Department of Energy (DOE), in conjunction with the U.S. wind industry, is supporting the development and commercialization of utility-grade wind turbines. Under the Certification Program, the DOE, through the National Renewable Energy Laboratory (NREL) will assist the U.S. industry in obtaining American Association for Laboratory Accreditation (A2LA)-type certification for their class of wind turbine. As part of the Certification Program, NREL is conducting a suite of certification tests that are specified by the International Electro-technical Commission standards.

One emerging certification requirement is to characterize the dynamic behavior of the wind turbine's operation. Therefore, the purpose of the dynamic characterization tests is to document the wind turbine's fundamental dynamic characteristics under critical operational modes and fault conditions in light of turbine design specifications. Some of the dynamic characteristics that we determine from testing include the conformation of fundamental structural vibration frequencies and the system's dynamic response to typical rated and extreme modes of operation.

This paper discusses NREL's approach in designing and implementing a dynamic characterization test for commercial wind turbines. One important objective of the dynamic characterization test is to provide a Certification Agent with test data to show that the wind turbine's mechanical equipment is operating within design vibration limits. For NREL's industry participant, the test results are an indication of the wind system's overall quality of mechanical operation that can be used to compare with established industry standards for a wind system's response under typical and extreme operating conditions.

14. SUBJECT TERMS wind turbines; testing; characterization; certification

15. NUMBER OF PAGES

16. PRICE CODE

17. SECURITY CLASSIFICATION OF REPORT Unclassified
18. SECURITY CLASSIFICATION OF THIS PAGE Unclassified
19. SECURITY CLASSIFICATION OF ABSTRACT Unclassified
20. LIMITATION OF ABSTRACT UL 